\title{
Analyze and prioritize strategic factors on the establishment of knowledge management in banks
}

\author{
Farshad SHOKROLLAHZADE ${ }^{1}$, Saeed Hakami NASAB ${ }^{1, *}$ \\ ${ }^{1}$ Shahrood University of Technology \\ *Corresponding author: Department of Management, Faculty of Industrial Engineering and \\ Management, Shahrood University of Technology, Shahrood, Iran. \\ E-mail: saeedhakami@shahroodut.ac.ir and saeedhakami@yahoo.com
}

\begin{abstract}
Introduction: Knowledge management covers all process and activities related to the creation, acquisition sharing and use knowledge, skills and expertise. At the present of time, if organization does not have information and new knowledge in according with global development will not be able to make the right decision. Addressing the issue of knowledge and knowledge management it is important to have knowledge because knowledge is an ultimate competitive advantage for new origination and the key to victory and it is the only source that is difficult or even impossible to imitate and copy.

Methods: This study is a descriptive survey. The study sample included all employees of Bank Hekmat Iranian are located in Tehran. According to the understanding of study population characteristics, simple random sampling method was used. In this study, on the framework Of Huang is studied: Team working, employee involvement, employee empowerment, knowledge structure, information system, training, commitment of senior management, benchmarking, performance measurement, organizational culture. The descriptive analysis of data using descriptive statistics and then through confirmatory factor analysis using SMART PLS software to inferential analysis of the hypothesis was done. Subsidiary hypothesis were studied and tested by One-Sample T-Test.

Results: The analyze performed on collated data, it was concluded that all elements of employee empowerment, infrastructure, information systems, organization culture, modeling, employee involvement, teamwork, commitment of senior managers, knowledge structure, staff training and performance measurement leads to successful implementation of knowledge management in Bank Hekmant Iranian. Prioritizing these factors, as well as to establish knowledge management model led to 1. Team working, 2. Employee involvement., 3. Employee Empowerment, 4. Knowledge structure, 5. Information System, 6. Training, 7. Commitment of senior management, 8. Benchmarking, 9. Performance measurement, 10. Organizational culture. Results of the analysis showed that the situation of organizational culture, employee empowerment and information systems infrastructure are significantly appropriate, the situation of commitment of senior management, staff training, teamwork, benchmarking and structure knowledge and performance measurement are partly appropriate.
\end{abstract}


Conclusion: Identifying factors affecting on successful implementation of knowledge management in Bank Hekmat Iranian may lead to identifying gaps in organizational knowledge, more productivity of human capital, efficient and effective learning of staff, providing more value-added services, customers and employees satisfaction, prevent the recurrence of errors, reduction duplication, saving time, stimulate motivation, creativity and innovation, and strengthening the competitive position of the bank.

Keywords: Knowledge, Knowledge management, Bank Hekmat Iranian, information system, infrastructure.

\section{Introduction}

At the present time, meet the needs of customers and employees is possible by using modern technology and keep pace with the world's information, the use of new technologies and save time and resources. The stability of an organization in today's changing world, along with the knowledge of the world and the use of modern scientific progress. If organizations do not have the information and new knowledge, then will not be able to obtain correct and timely decisions. The competitiveness of organizations in the current economic conditions include:

1. Tangible and intangible resources become knowledge

2. Information systems are focused on knowledge management (rather than management)

If business systems to gain knowledge in the organization effectively, and use it for business processes so have the products and services that have a competitive advantage in the market. There are many organizations as knowledge-based businesses. Today, organizations that consider competitiveness in the market as the central theme, they use of knowledge management as one of their effective activities. On the other hand, given that failure rate is remarkable in knowledge management projects, Understanding the critical factors can contribute to the success of the business systems in needs assessment, planning, execution and implementation of knowledge management and ultimately decreasing the probability of failure in knowledge management projects. The main importance and application of critical success factors in knowledge management system are:

By identifying control over these factors, organizations will ensure the successful implementation of a knowledge management system. So any activity in this area should be pre-planned and perform on the favorable performance on factors of success. The main question in this research is that "Hekmat Iranian bank plans to implement knowledge management in their organization and to be informed of the status of this infrastructure in their organization. By measuring the level of deployment processes and infrastructure factors, determined the level of knowledge management in the bank and determined the distance between the existing and desired level by comparing these two levels in the organization. For better implementation of knowledge management system is required to identify the assumptions and the necessary fields and check their status to implement knowledge management. On the one hand it is 
the need to get tacit knowledge in employees of the bank. This is impossible when there is not a powerful and integrated knowledge management system.

In this context there is a question: what are the main factors in successful implementation of knowledge management systems in Hekmat Iranian bank?

What is the current situation and the readiness of the infrastructure and processes knowledge management system in the bank? Is it possible to implement the system provided in the bank? What are the priorities of infrastructures in order to provide appropriate solutions?

According to the above-mentioned questions, done ranking of critical factors in the successful implementation of knowledge management systems in banks, identification and evaluation and the importance of this factors.

The remaining paper is organized as follows:

Second part is devoted to a review of "Literature" subject, third section is related to the "Methodology", fourth part is about the "analyze, prioritize, and naming the main factors underlying successful implementation of knowledge management in the Hekmat Bank", and the fifth section is devoted to the "Discussion and Conclusion"

\section{Literature of study}

Critical success factors can be defined as areas that will ensure successful competitive performance for the organization, only on the condition that their results are satisfactory. Rockhart (1979) defines critical success factors as areas that would ensure success if the results are satisfactory. All factors that can contribute to the successful implementation of knowledge management are observed in the literature.

But despite this, cannot be seen working on the systematic identification of a coherent set of critical success factors in implementing knowledge management in Hekmat Iranian Bank. Studies on the implementation of knowledge management is focused on large industrial organizations in developed countries. Therefore, this factors are mainly related to large industrial organizations and also reflect the circumstances and needs of these types of organizations. Implementation critical success factors in the Hekmat Iranian Bank is not proper if there is not understanding of the situation. Therefore, there is need to develop appropriate approaches to knowledge management in the banking business (Azim and zayeri 2003).

In research conducted at the Institute of Research and Educational Planning \& Management

As "key success factors of knowledge management systems in universities and higher education centers of management in Tehran " (Fatih Mohammadi et al., 2009), seven infrastructure and basic factors were identified:

1. Knowledge-based strategic orientation

2. Participatory Culture 
3. Evaluation and knowledge transfer

4. Infrastructure information systems

5. human recourse development

6. Modeling

7. Involvement of people

Research on the effectiveness of knowledge management in Iranian governmental bodies (using the Delphi method and management approach) has shown that the following factors are affect on effectiveness of this type of system (Abtahi and Salavati, 2006):

1. Culture Knowledge Creation

2. Knowledge Leadership

3. Knowledge resources

4. Knowledge ports

5. Knowledge-based structures

6. Knowledge-based processes

7. Environmental factors (political, cultural, technological)

8. Citizenry

In 1386, Mr. Hadi examined a comprehensive suite of knowledge management success factors (in the form of a thesis entitled "Assessment of effective factors on the success of knowledge management in project-based organizations"

According to the study results, 10 general factors was confirmed that includes of:

43 indices extracted for the success of knowledge management projects and final approval 23 indicators of above indices.

Given these factors, the researcher has designed 10 hypothesis, suggesting that these factors have high impact to knowledge management and all hypotheses have been confirmed.

Akhavan et.al have done other research. In this study, 16 factors was selected from between 33 primary factors.

These factors include the: Interactions and Relationships, Job security, The risk appetite of the organization, Human resources management, team working, Knowledge sharing, Preparedness organizations to adopt knowledge management, A systematic approach to knowledge management, Designers of knowledge management system, Technological tools and knowledge databases for research, Repositories of knowledge, performance evaluation, Modeling, Chief Knowledge Officer.

Kambiz Talebi, and Mehdi Salimi Torkamani conducted an investigation and determined in this study the main factors and sub-factors. They also determined the importance and priority of this factors (based on a detailed study of critical success factors in the implementation of knowledge management). The study identified eight critical success factors in the implementation of knowledge management in 
tooling companies associated with Iran Khodro. These factors were ranked according to their importance (high importance to importance): Strategic management, organizational infrastructure, culture, human resource management, and process, measure the success of knowledge management, enterprise resource and competitive benchmarking. Based on our findings, the three factors (strategic management, organizational and cultural infrastructure) were identified as the most critical success factors, the views of professionals and experts of tooling industry. Competitive Benchmarking and enterprise resources have the lowest rank.

Genghis Valmhmdy 2010, in a study based on a detailed study of the main factors in successful implementation of knowledge management (in small and medium organizations), analyzed the 12 critical success factors:

Support from top management, organizational culture, technological infrastructure, strategy, knowledge management, performance measurement, organizational infrastructure, activities and processes, rewards and incentives, constraints, resources, education and training, Human resource management, benchmarking analysis based on leadership and support from senior management from the perspective of researchers.

Nusseibeh Salary and colleagues (2012), have identified 31 sub-agent in the form of seven main factors: staffing, strategy, management, evaluation, organizational culture, processes and information technology.

Their research was performed as title "Identify and prioritize the factors affecting the success of knowledge management in science and technology park"

In this study, prioritization of factors are as follows:

Human resources, strategy, management, organizational culture, process, assess and Information Technology

The results of the study (Hussein ABdolmaleky et al. 2015) entitled "Review and prioritize the factors affecting the establishment of a knowledge management system in the Ministry of Sport and Youth" states that among the factors, information technology, corporate culture, organizational structure plays a significant role on the implementation of the system and factors such as strategy don't plays a decisive role. Among the four factors mentioned, the corporate culture is the most important and influential factor.

Askayrm and Amidon (1997) identified seven key factors to these fields.These factors include the:

Strong links with business requirements, architecture and landscape mandatory, knowledge management, knowledge creation and knowledge sharing culture, continuous learning, technological infrastructure and processes of organizational knowledge.

Davenport and Prusak (1998) conducted a study on 31 projects in 24 companies. The purpose of this study was factors that could lead to more effective in organizations. Before anything, they assessed 
their impact on project performance and then organizational success factors were extracted through. 18 projects were selected. Among these projects, eight factors were selected as factors of successful knowledge management system.

Wang and spin vall (2005) noted a number of management's factors that were effective on the successful implementation of a knowledge management system.

Factors found by the researchers consisted of 11 cases are as follows: Leadership support and leadership, culture, information technology, strategy and objectives, evaluation, infrastructure, activities and organizational processes, incentives, resources, training and human resource management. It is noteworthy that Huang's model (2005) was chosen as the base model.

\subsection{Research Hypothesis}

First hypothesis: organizational culture suitable for the establishment of a knowledge management system in the Hekmat Iranian Bank

Second hypothesis: the commitment of senior managers is suitable for implementing knowledge management in the bank

Third hypothesis: the status of employee involvement is appropriate to deploy this system in the bank

Fourth hypothesis: the training is suitable for the establishment of a knowledge management system in the bank.

Fifth hypothesis: the team working is suitable for the establishment of a knowledge management system in the bank

Sixth hypothesis: Status empowerment is suitable for the establishment of a knowledge management system in the bank.

Seventh hypothesis: the infrastructure of information systems suitable for the establishment of a knowledge management system in the bank.

Eighth hypothesis: measure the performance management system is suitable for deployment in the bank

Ninth hypothesis: the modeling is suitable for implementing knowledge management in banks.

Hypothesis tenth: Status "body of knowledge" is suitable for deployment in the bank system.

\section{Methodology}

The research design and statistical methods

This study is a descriptive - survey. 
Description: This is a descriptive research because it pays to describe the state of infrastructure

Scrolling: This is a survey research, because the field has been investigated by survey. The population of this research includes all employees in the Hekman Iranian Bank. The size of this population consists of 26 bank branches of Hekmat Iranian Bank located in Tehran,

The study used random sampling methods. According to the understanding and study of the characteristics of the study population, this study makes use of simple sampling. Accordingly, using Cochran equation, 111 subjects were selected (out of 156 employees in the bank) that from the 111 questionnaires distributed, 111 questionnaires were completed and returned.

According to the research method, questionnaire is the most useful tool in the research the researchers used the questionnaire "Hung" for subject review. The period of study is in 1394 research is carried out in Tehran. Research topic is related to knowledge management and factors affecting the implementation that include of: Culture, senior management, education, participation, team, empowerment, information systems, performance measurement, modeling, knowledge structure.

After collecting raw data related to the tests, descriptive and inferential analysis was performed on the assumptions presented above. Therefore, the raw data were analyzed by SPSS software. First, descriptive analysis was performed using descriptive statistics, then, confirmatory factor analysis was performed using the software SMART PLS.

\subsection{Validity and Reliability of questionnaire:}

To measure the content validity, the questionnaire (which includes indicators of knowledge management) is used narrative structure. The narrative structure is selected to test the significance of the markers. The narrative structure is selected to test the significance of the markers which shows whether the markers have the structures and platforms in order to measure the structures studied in the research model.

Estimate the measurement model needs to check the validity of two types: Convergent validity and diagnostic validity. Convergent validity shows the correlation between similar structures (theoretical perspective) and the diagnostic validity shows a specified structure of other structures.

In general, these two validity has shown the goodness of fit in the measurement model. For this purpose, according to the study, using SMART PLAS software and using confirmatory factor analysis, The construct validity of the questionnaire is calculated from the perspective of convergent validity and divergent validity. 
Bulletin de la Société Royale des Sciences de Liège, Vol. 86, special edition, 2017, p. 808 - 830

Table 1: Results related to validity

\begin{tabular}{|c|c|c|}
\hline \multicolumn{1}{|c|}{ Variable's name } & Components & $\begin{array}{c}\text { Reliability } \\
\text { capacity }\end{array}$ \\
\hline \multirow{3}{*}{$\begin{array}{c}\text { Infrastructure factors in the implementation of } \\
\text { knowledge management }\end{array}$} & Staff empowerment & 0.7 \\
\cline { 2 - 3 } & $\begin{array}{c}\text { Infrastructure information } \\
\text { systems }\end{array}$ & 0.73 \\
\cline { 2 - 3 } & Organization's culture & 0.76 \\
\cline { 2 - 3 } & Modeling & 0.76 \\
\cline { 2 - 3 } & Employee participation & 0.77 \\
\cline { 2 - 3 } & Team working & 0.85 \\
\hline \multirow{5}{*}{$\begin{array}{c}\text { Senior management } \\
\text { commitment }\end{array}$} & 0.75 \\
\cline { 2 - 3 } & Knowledge structure & 0.83 \\
\cline { 2 - 3 } & Employee's training & 0.8 \\
\cline { 2 - 3 } & performance evaluation & 0.85 \\
\cline { 2 - 3 } & &
\end{tabular}

Table 2: The amount of Skewness, kurtosis, standard deviation error of skewness and kurtosis of implementation of knowledge management

\begin{tabular}{|l|c|c|c|c|c|}
\hline Indexes & Skewness & $\begin{array}{c}\text { Standard } \\
\text { deviation }\end{array}$ & Kurtosis & $\begin{array}{c}\text { Standard } \\
\text { deviation error }\end{array}$ & $\begin{array}{c}\text { Kurtosis } \\
\text { deviation }\end{array}$ \\
\hline Organization's culture & -0.124 & 0.229 & -0.872 & 0.455 & \\
\hline $\begin{array}{l}\text { Senior management } \\
\text { commitment }\end{array}$ & -0.068 & 0.229 & -0.102 & 0.455 & \\
\hline Employee participation & 0.123 & 0.229 & -0.651 & 0.455 & \\
\hline Staff training & -0.046 & 0.229 & -0.532 & 0.455 & \\
\hline Team working & 0.078 & 0.229 & -0.157 & 0.455 & \\
\hline Staff empowerment & -0.159 & 0.229 & -0.459 & 0.455 & \\
\hline $\begin{array}{l}\text { Infrastructure information } \\
\text { systems }\end{array}$ & -0.224 & 0.229 & -0.65 & 0.455 & \\
\hline performance evaluation & 0.042 & 0.229 & -0.004 & 0.455 & \\
\hline Modeling & -0.269 & 0.229 & -0.59 & 0.455 & \\
\hline Knowledge structure & -0.593 & 0.229 & -0.263 & 0.455 & \\
\hline
\end{tabular}

Confirmatory factor analysis determined using indicators such as the value of $\mathrm{T}$, internal consistency reliability, standard error, In addition to the factor loading, each of the items shown in the data analysis (by separation components). Construct reliability coefficient is variable among 0to 10. Values higher than 0.7 are acceptable. Internal Consistency or internal stability can estimate with a reliability 
coefficient such as Cronbach's alpha. For the purpose of this test, ensuring reliability is suitable in the range of 6 to $8 \%$. In this context, respondents have answered the questions very carefully and very deliberately.

\section{Findings}

Demographic statistics in this study consists of: Gender, Age, Background of financial services, Level of Education which are as follows:

Subjects are $55 \%$ female, $45 \%$ male. $85.58 \%$ of them were aged $25-35,6.3 \%$ sre aged $36-45,8.1 \%$ were aged 46-55. 90.09\% of them had 1-10 years work experience, $0.9 \%$ had 21-30 years and 8.1\% had 11-20 years. Between them, 7.2\% of them had diploma, 10.8\% had Associated diploma, 55\% had bachelor, $27 \%$ had MA. $45 \%$ of them were single and 55\% get married.

Study's field of them are as follows:

1.8 banking , 9\% MBA management , $21.6 \%$ industrial engineering, 31.5\% accounting, $23.4 \%$ business management, 5.4\% Statistics and Mathematics, 6.3\% Information Technology,6.35 computer engineering. Statistical test in analyzing hypotheses is as follows:

The first hypothesis: Organizational culture leads to the successful implementation of knowledge management in bank Hekmat Iranian

Table 3: related results of confirmatory factor analysis on organizational culture

\begin{tabular}{|c|c|c|c|c|c|c|c|}
\hline & Questions & $\begin{array}{c}\text { Factor } \\
\text { loading }\end{array}$ & $\begin{array}{c}\text { Statistics } \\
\mathrm{T}\end{array}$ & $\begin{array}{c}\text { Standard } \\
\text { error }\end{array}$ & $\begin{array}{c}\text { Reliability } \\
\text { capacity }\end{array}$ & $\begin{array}{c}\text { Cronbach's } \\
\text { alpha. }\end{array}$ & $\begin{array}{c}\mathrm{R} \\
\text { Square }\end{array}$ \\
\hline $\begin{array}{c}\text { Organizational } \\
\text { culture }\end{array}$ & 1 & 0.74 & 17.6 & 0.04 & 0.76 & 0.58 & 0.4 \\
\hline & 2 & 0.62 & 10.4 & & & & \\
\hline & 3 & 0.77 & 17.41 & & & & \\
\hline & 4 & 0.5 & 7.59 & & & & \\
\hline
\end{tabular}

\section{Results}

The table above shows that the factor loadings are higher than the average 5.0 - related to all of the statements of organizational culture - Factor loadings contain more than 0.7 , are more appropriate. Since all the statements of organizational culture have a T-Value much higher than 1.96, Thus, the factor loadings of all the items is at 0.95 confidence level. So it can say, organizational culture leads to the successful implementation of knowledge management in bank Hekmat Iranian. Reliability "Cornbrash's alpha " organizational culture is equal to 0.58 So it can say that organizational culture assessment tool is enjoyed good reliability CR is much higher than the 0.7 - related to organizational culture - which represents the acceptable optimal combination of reliability. 
The second hypothesis: commitment of senior managers leading to the successful implementation of knowledge management in Hekmat Iranian Bank:

Table4: Related results of confirmatory factor analysis on senior management commitment

\begin{tabular}{|l|c|c|c|c|l|c|c|}
\hline Factor & Questions & $\begin{array}{l}\text { Factor } \\
\text { loading }\end{array}$ & $\begin{array}{l}\text { Statistics } \\
\mathrm{T}\end{array}$ & $\begin{array}{l}\text { Standard } \\
\text { error }\end{array}$ & $\begin{array}{l}\text { Reliability } \\
\text { capacity }\end{array}$ & $\begin{array}{l}\text { Cronbach's } \\
\text { alpha. }\end{array}$ & $\begin{array}{l}\text { R } \\
\text { Square }\end{array}$ \\
\hline $\begin{array}{l}\text { Senior management } \\
\text { commitment }\end{array}$ & 5 & 0.7 & 14.7 & 0.02 & 0.75 & 0.56 & 0.66 \\
\hline & 6 & 0.57 & 10.52 & & & & \\
\hline & 7 & 0.65 & 14.19 & & & & \\
\hline & 8 & 0.72 & 18.21 & & & & \\
\hline
\end{tabular}

The result of above table shows that factor loadings of all the statements of senior management commitment are higher than the average 0.5 , load factor greater than 0.7 are more suitable. Given that all the items have a T-Value higher than 1.96, so, factor loadings are within a confidence level of $95 \%$. So it can be said that senior management commitment leads to successful implementation of knowledge management in bank. Reliability "Cronbach's alpha" of senior manager's commitment are equal with 0.56 . So it can be said that the commitment of senior managers have good reliability assessment tool. CR for this hypothesis is much higher than 0.7. This proves that Composite reliability is desirable and acceptable.

The third hypothesis: the employees' contribution leadings to the successful implementation of knowledge management in bank Hekmat Iranian

Table 5: Related results of confirmatory factor analysis on Employee participation

\begin{tabular}{|l|c|c|c|c|c|c|c|}
\hline Factor & Questions & $\begin{array}{c}\text { Factor } \\
\text { loading }\end{array}$ & $\begin{array}{c}\text { Statistics } \\
\mathrm{T}\end{array}$ & $\begin{array}{c}\text { Standard } \\
\text { error }\end{array}$ & $\begin{array}{c}\text { Reliability } \\
\text { capacity }\end{array}$ & $\begin{array}{c}\text { Cronbach's } \\
\text { alpha. }\end{array}$ & $\begin{array}{c}\mathrm{R} \\
\text { Square }\end{array}$ \\
\hline $\begin{array}{l}\text { Employee } \\
\text { participation }\end{array}$ & 9 & 0.72 & 27.71 & 0.01 & 0.77 & 0.62 & \\
\hline & 10 & 0.77 & 25.09 & & & & \\
\hline & 11 & 0.61 & 12.39 & & & & \\
\hline & 12 & 0.62 & 01394 & & & & \\
\hline & 13 & 0.42 & 4.85 & & & & \\
\hline
\end{tabular}

The result of above table shows that factor loadings of all the statements of employee's contribution are higher than the average 0.5 , load factor greater than 0.7 are more suitable. Given that all the items have a T-Value higher than 1.96, so, factor loadings are within a confidence level of $95 \%$. So it can be said that employee's contribution leads to successful implementation of knowledge management in bank. Reliability " Cronbach's alpha " of employee's contribution are equal with 0062 So it can be said that 
the employee's contribution have good reliability assessment tool. CR for this hypothesis is much higher than 0.7. This proves that Composite reliability is desirable and acceptable.

The fourth hypothesis: the Staff training leadings to the successful implementation of knowledge management in bank Hekmat Iranian

Table 5: Results of confirmatory factor analysis on Employee participation

\begin{tabular}{|l|c|c|c|c|c|c|c|}
\hline Factor & Questions & $\begin{array}{c}\text { Factor } \\
\text { loading }\end{array}$ & $\begin{array}{c}\text { Statistics } \\
\mathrm{T}\end{array}$ & $\begin{array}{c}\text { Standard } \\
\text { error }\end{array}$ & $\begin{array}{c}\text { Reliability } \\
\text { capacity }\end{array}$ & $\begin{array}{c}\text { Cronbach's } \\
\text { alpha. }\end{array}$ & $\begin{array}{c}\mathrm{R} \\
\text { Square }\end{array}$ \\
\hline $\begin{array}{l}\text { Employee } \\
\text { participation }\end{array}$ & 9 & 0.72 & 27.71 & 0.77 & .0 .62 & 0.72 & \\
\hline
\end{tabular}

The result of above table shows that factor loadings of all the statements of Staff training are higher than the average 0.5 , load factor greater than 0.7 are more suitable. Given that all the items have a TValue higher than 1.96, so, factor loadings are within a confidence level of $95 \%$. So it can be said that Staff training leads to successful implementation of knowledge management in bank. Reliability "Cronbach's alpha" of Staff training are equal with 0062 so it can be said that the Staff training have good reliability assessment tool. CR for this hypothesis is much higher than 0.7 . This proves that Composite reliability is desirable and acceptable.

The fifth hypothesis: the Team working leadings to the successful implementation of knowledge management in bank Hekmat Iranian

Table 6: results of confirmatory factor analysis on Employee participation

\begin{tabular}{|l|l|l|l|l|l|l|l|}
\hline Factor & Questions & $\begin{array}{l}\text { Factor } \\
\text { loading }\end{array}$ & $\begin{array}{l}\text { Statistics } \\
\text { T }\end{array}$ & $\begin{array}{l}\text { Standard } \\
\text { error }\end{array}$ & $\begin{array}{l}\text { Reliability } \\
\text { capacity }\end{array}$ & $\begin{array}{l}\text { Cronbach's } \\
\text { alpha. }\end{array}$ & $\begin{array}{l}\text { R } \\
\text { Square }\end{array}$ \\
\hline $\begin{array}{l}\text { Team } \\
\text { working }\end{array}$ & 19 & 0.75 & 27.43 & 0.85 & 0.73 & 0.6 & \\
\hline & 20 & 085 & 37.33 & & & & \\
\hline & 21 & 0.82 & 37.83 & & & & \\
\hline
\end{tabular}

The result of above table shows that factor loadings of all the statements of team working are higher than the average 0.5, load factor greater than 0.7 are more suitable. Given that all the items have a TValue higher than 1.96, so, factor loadings are within a confidence level of $95 \%$. So it can be said that team working leads to successful implementation of knowledge management in bank. Reliability " Cronbach's alpha " of team working are equal with 0062 So it can be said that the team working have good reliability assessment tool. CR for this hypothesis is much higher than 0.7 . This proves that Composite reliability is desirable and acceptable. 
The sixth hypothesis: the empowerment leadings to the successful implementation of knowledge management in bank Hekmat Iranian

Table 7: Results of confirmatory factor analysis on empowerment

\begin{tabular}{|l|c|c|c|c|c|c|c|}
\hline Factor & Questions & $\begin{array}{c}\text { Factor } \\
\text { loading }\end{array}$ & $\begin{array}{c}\text { Statistics } \\
\mathrm{T}\end{array}$ & $\begin{array}{c}\text { Standard } \\
\text { error }\end{array}$ & $\begin{array}{c}\text { Reliability } \\
\text { capacity }\end{array}$ & $\begin{array}{c}\text { Cronbach's } \\
\text { alpha. }\end{array}$ & $\begin{array}{c}\mathrm{R} \\
\text { Square }\end{array}$ \\
\hline Empowerment & 22 & 0.67 & 12.19 & 0.02 & 0.7 & 0.13 & 0.5 \\
\hline & 23 & 0.79 & 19.98 & & & & \\
\hline
\end{tabular}

The result of above table shows that factor loadings of all the statements of empowerment are higher than the average 0.5 , load factor greater than 0.7 are more suitable. Given that all the items have a TValue higher than 1.96, so, factor loadings are within a confidence level of $95 \%$. So it can be said that empowerment leads to successful implementation of knowledge management in bank. Reliability " Cornbrash's alpha" of empowerment are equal with 0.13 so it can be said that the empowerment have good reliability assessment tool. CR for this hypothesis is much higher than 0.7 . This proves that Composite reliability is desirable and acceptable

The seventh hypothesis: the Infrastructure information systems leadings to the successful implementation of knowledge management in bank Hekmat Iranian

Table 8: results of confirmatory factor analysis on Infrastructure information system

\begin{tabular}{|l|c|c|c|c|c|c|c|}
\hline Factor & Questions & $\begin{array}{c}\text { Factor } \\
\text { loading }\end{array}$ & $\begin{array}{c}\text { Statistics } \\
\mathrm{T}\end{array}$ & $\begin{array}{c}\text { Standard } \\
\text { error }\end{array}$ & $\begin{array}{c}\text { Reliability } \\
\text { capacity }\end{array}$ & $\begin{array}{c}\text { Cronbach's } \\
\text { alpha. }\end{array}$ & $\begin{array}{c}\mathrm{R} \\
\text { Square }\end{array}$ \\
\hline $\begin{array}{l}\text { Infrastructure } \\
\text { information } \\
\text { system }\end{array}$ & 24 & 0.63 & 10.11 & 0.03 & 0.73 & 0.45 & 0.45 \\
\hline & 25 & 0.74 & 15.54 & & & & \\
\hline & 26 & 0.68 & 10.52 & & & & \\
\hline
\end{tabular}

The result of above table shows that factor loadings of all the statements of Infrastructure information systems are higher than the average 0.5 , load factor greater than 0.7 are more suitable. Given that all the items have a T-Value higher than 1.96, so, factor loadings are within a confidence level of $95 \%$. So it can be said that Infrastructure information systems leads to successful implementation of knowledge management in bank. Reliability " Cronbach's alpha " of Infrastructure information systems are equal with 0.45 So it can be said that the Infrastructure information systems have good reliability assessment tool. CR for this hypothesis is much higher than 0.7. This proves that Composite reliability is desirable and acceptable. 
The eighth hypothesis: the performance evaluation systems leadings to the successful implementation of knowledge management in bank Hekmat Iranian

Table 9: Results of confirmatory factor analysis on performance evaluation

\begin{tabular}{|l|c|c|c|c|c|c|c|}
\hline Factor & Questions & $\begin{array}{c}\text { Factor } \\
\text { loading }\end{array}$ & $\begin{array}{c}\text { Statistics } \\
\mathrm{T}\end{array}$ & $\begin{array}{c}\text { Standard } \\
\text { error }\end{array}$ & $\begin{array}{c}\text { Reliability } \\
\text { capacity }\end{array}$ & $\begin{array}{c}\text { Cronbach's } \\
\text { alpha. }\end{array}$ & $\begin{array}{c}\text { R } \\
\text { Square }\end{array}$ \\
\hline $\begin{array}{l}\text { performance } \\
\text { evaluation }\end{array}$ & 27 & 0.69 & 14 & 0.01 & 0.85 & 0.77 & 0.72 \\
\hline & 28 & 0.75 & 20.8 & & & & \\
\hline & 29 & 0.75 & 20.8 & & & & \\
\hline & 30 & 0.82 & 39.83 & & & & \\
\hline
\end{tabular}

The result of above table shows that factor loadings of all the statements of performance evaluation are higher than the average 0.5 , load factor greater than 0.7 are more suitable. Given that all the items have a T-Value higher than 1.96, so, factor loadings are within a confidence level of $95 \%$. So it can be said that performance evaluation leads to successful implementation of knowledge management in bank. Reliability " Cronbach's alpha " of performance evaluation are equal with 0.77 . So it can be said that the performance evaluation have good reliability assessment tool. CR for this hypothesis is much higher than 0.7. This proves that Composite reliability is desirable and acceptable.

The ninth hypothesis: the modeling leadings to the successful implementation of knowledge management in bank Hekmat Iranian

Table 10: results of confirmatory factor analysis on modeling

\begin{tabular}{|l|c|c|c|c|c|c|c|}
\hline Factor & Questions & $\begin{array}{c}\text { Factor } \\
\text { loading }\end{array}$ & $\begin{array}{c}\text { Statistics } \\
\mathrm{T}\end{array}$ & $\begin{array}{c}\text { Standard } \\
\text { error }\end{array}$ & $\begin{array}{c}\text { Reliability } \\
\text { capacity }\end{array}$ & $\begin{array}{c}\text { Cronbach's } \\
\text { alpha. }\end{array}$ & $\begin{array}{c}\mathrm{R} \\
\text { Square }\end{array}$ \\
\hline Modeling & 31 & 0.57 & 10.21 & 0.03 & 0.76 & 0.53 & 0.6 \\
\hline & 32 & 0.81 & 24.78 & & & & \\
\hline & 33 & 0.75 & 31.04 & & & & \\
\hline
\end{tabular}

The result of above table shows that factor loadings of all the statements of modeling are higher than the average 0.5 , load factor greater than 0.7 are more suitable. Given that all the items have a T-Value higher than 1.96, so, factor loadings are within a confidence level of $95 \%$. So it can be said that modeling leads to successful implementation of knowledge management in bank. Reliability "Cronbach's alpha" of modeling are equal with 0.53 . So it can be said that the modeling have good reliability assessment tool. CR for this hypothesis is much higher than 0.7 . This proves that Composite reliability is desirable and acceptable 
The tenth hypothesis: the Knowledge structure leadings to the successful implementation of knowledge management in bank Hekmat Iranian

Table 11: results of confirmatory factor analysis on knowledge structure

\begin{tabular}{|l|c|c|c|c|c|c|c|}
\hline Factor & Questions & $\begin{array}{c}\text { Factor } \\
\text { loading }\end{array}$ & $\begin{array}{c}\text { Statistics } \\
\mathrm{T}\end{array}$ & $\begin{array}{c}\text { Standard } \\
\text { error }\end{array}$ & $\begin{array}{c}\text { Reliability } \\
\text { capacity }\end{array}$ & $\begin{array}{c}\text { Cronbach's } \\
\text { alpha. }\end{array}$ & $\begin{array}{c}\mathrm{R} \\
\text { Square }\end{array}$ \\
\hline $\begin{array}{l}\text { knowledge } \\
\text { structure }\end{array}$ & 34 & 0.71 & 15.86 & 0.03 & 0.83 & 0.7 & 0.56 \\
\hline & 35 & 0.75 & 22.9 & & & & \\
\hline & 36 & 0.89 & 80.95 & & & & \\
\hline
\end{tabular}

The result of above table shows that factor loadings of all the statements of Knowledge structure are higher than the average 0.5, load factor greater than 0.7 are more suitable. Given that all the items have a T-Value higher than 1.96, so, factor loadings are within a confidence level of $95 \%$. So it can be said that Knowledge structure leads to successful implementation of knowledge management in bank. Reliability "Cronbach's alpha " of Knowledge structure are equal with 0.7. So it can be said that the Knowledge structure have good reliability assessment tool. CR for this hypothesis is much higher than 0.7. This proves that Composite reliability is desirable and acceptable.

\subsection{Convergent validity}

Convergent validity is based on the principle that - indicators of each structure have a moderate correlation with each other - criteria for convergent validity is that value of output variance average (AVE) is more than 0.5. Table 12 shows the results of "team working, empowerment, performance measurement, modeling and structured knowledge" are possessed of convergent validity

Table 12: value of output variance average (AVE)

\begin{tabular}{|l|c|c|}
\hline Indexes & Number of statements & Convergent validity \\
\hline Organizational culture & 4 & 0.44 \\
\hline Senior management commitment & 4 & 0.43 \\
\hline Employee participation & 5 & 0.41 \\
\hline Staff training & 5 & 0.43 \\
\hline Team working & 3 & 0.65 \\
\hline Empowerment & 2 & 0.53 \\
\hline Infrastructure information systems & 3 & 0.47 \\
\hline Performance evaluation & 4 & 0.6 \\
\hline Modeling & 3 & 0.51 \\
\hline Knowledge structure & 3 & 0.63 \\
\hline
\end{tabular}




\subsection{Divergent Validity}

Divergent validity states that there are partial correlations between indicators of structural and other indicators. Accordingly, the square root of AVE value In any structure is more than other the structural correlation with other structures. As seen in table 13, given that square of AVE in all structures are more than the correlation between of these structures with other structures, therefore, measuring tools impacts of the proper divergent validity.

Table 13: The correlation matrix structures

\begin{tabular}{|l|c|c|c|c|c|c|c|c|c|c|c|}
\hline Indexes & 1 & 2 & 3 & 4 & 5 & 6 & 7 & 8 & 9 & 10 & $\begin{array}{c}\text { Square } \\
\text { (AVE) }\end{array}$ \\
\hline $\begin{array}{l}\text { Organizational } \\
\text { culture }\end{array}$ & 1 & & & & & & & & & 0.66 \\
\hline $\begin{array}{l}\text { Senior } \\
\text { management } \\
\text { commitment }\end{array}$ & $0.65^{* *}$ & 1 & & & & & & & & 0.65 \\
\hline $\begin{array}{l}\text { Employee } \\
\text { participation }\end{array}$ & $0.46^{* *}$ & $0.6^{* *}$ & 1 & & & & & & & 0.64 \\
\hline Staff training & $0.47^{* *}$ & $0.66^{* *}$ & $0.66^{* *}$ & 1 & & & & & & 0.66 \\
\hline Team working & $0.42^{* *}$ & $0.7^{* *}$ & $0.56^{* *}$ & $0.6^{*}$ & 1 & & & & & 0.8 \\
\hline Empowerment & $0.34^{* *}$ & $0.48^{* *}$ & $0.52^{* *}$ & $0.7^{* *}$ & $0.44^{* *}$ & 1 & & & & 0.53 \\
\hline $\begin{array}{l}\text { Infrastructure } \\
\text { information } \\
\text { systems }\end{array}$ & $0.41^{* *}$ & $0.51^{* *}$ & $0.49^{* *}$ & $0.54^{* *}$ & $0.51^{* *}$ & $0.43^{* *}$ & 1 & & & 0.68 \\
\hline $\begin{array}{l}\text { Performance } \\
\text { evaluation }\end{array}$ & $0.49^{* *}$ & $0.63^{* *}$ & $0.76^{* *}$ & $0.67^{* *}$ & $0.58^{* *}$ & $0.54^{* *}$ & $0.52^{* *}$ & 1 & & 0.77 \\
\hline Modeling & $0.31^{* *}$ & $0.45^{* *}$ & $0.7^{* *}$ & $0.6^{* *}$ & $0.67^{* *}$ & $0.52^{* *}$ & $0.44^{* *}$ & $0.67^{* *}$ & & 1 \\
\hline $\begin{array}{l}\text { Knowledge } \\
\text { structure }\end{array}$ & 0.33 & $0.57^{* *}$ & $0.6^{* *}$ & $0.42^{* *}$ & $0.65^{* *}$ & $0.42^{* *}$ & $0.56^{* *}$ & 0.48 & & 0.79 \\
\hline
\end{tabular}


Bulletin de la Société Royale des Sciences de Liège, Vol. 86, special edition, 2017, p. 808 - 830

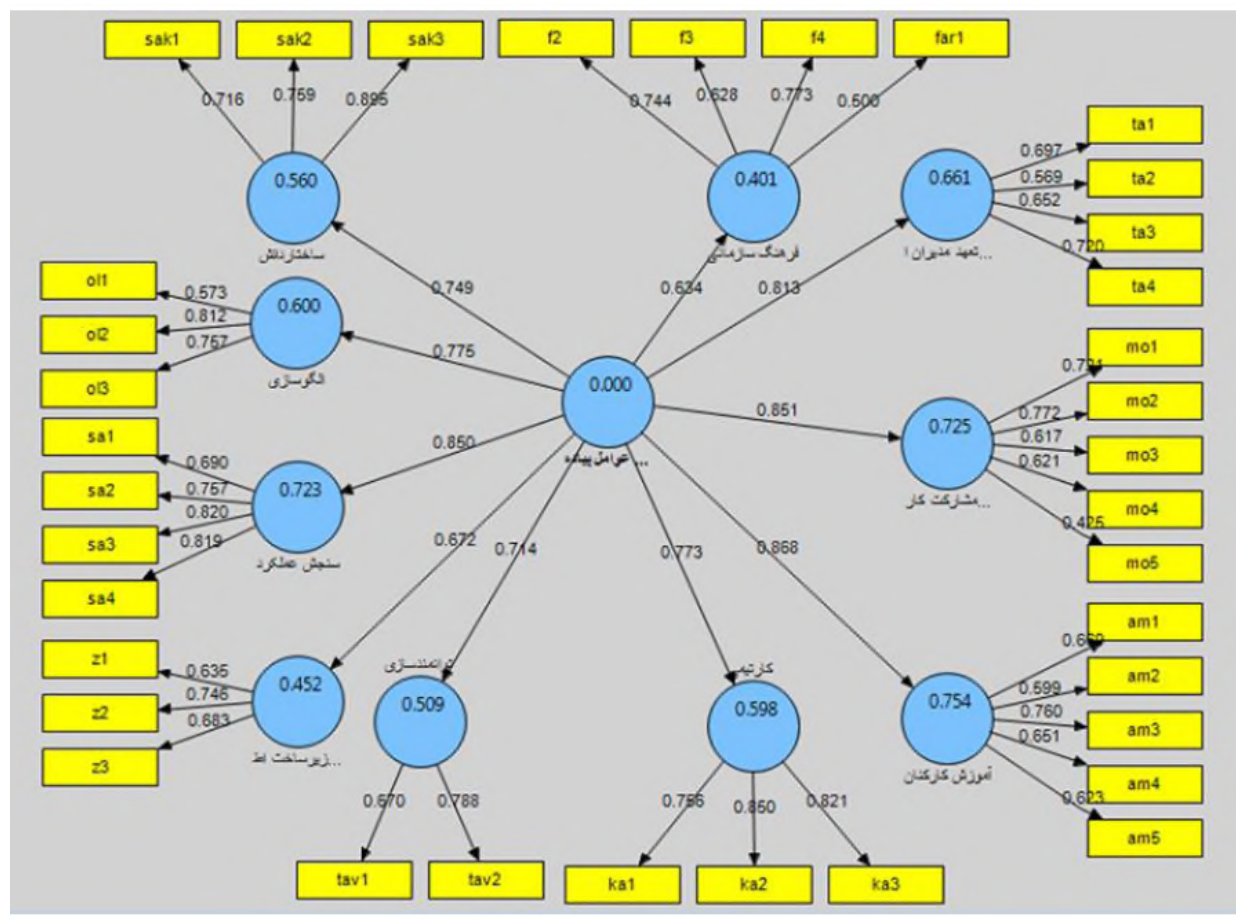

Figure 1: Load factor associated with Factor structure model of Implementation of knowledge management factors.

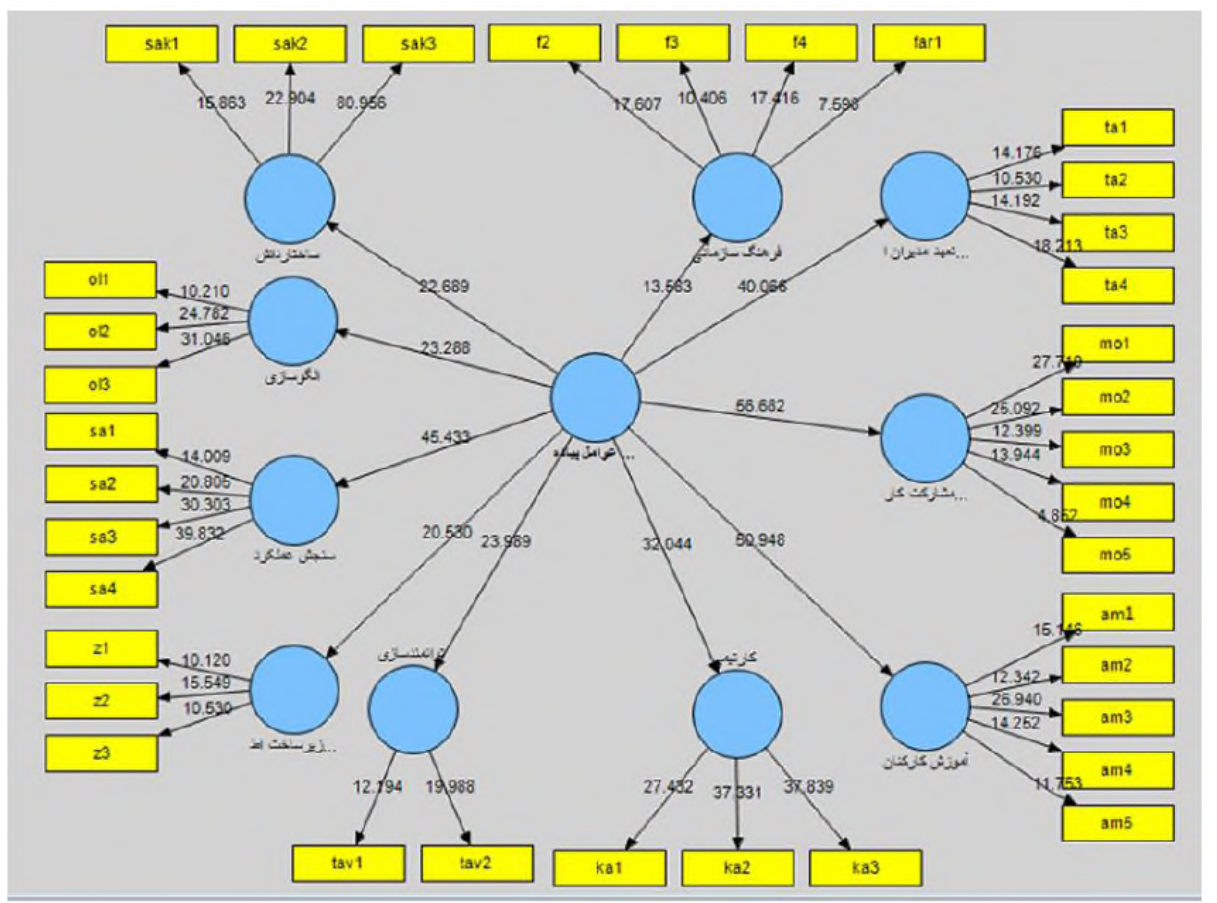

Figure 2: Significant values T related to the factor structure model of Implementation of knowledge management 
Prioritize of Implementation of knowledge management factors

To prioritize the implementation of knowledge management act as follows:

Average value for each factor divided on the number of questions. The values obtained for each factor compared with the other factors. In the following table is shown the results of prioritized each of the implementation of knowledge management factors.

Table 14: Prioritize the implementation of knowledge management factors

\begin{tabular}{|l|c|c|}
\hline Factors & Average & Priority \\
\hline Empowerment & 3.49 & First \\
\hline Infrastructure information systems & 3.47 & Second \\
\hline Organizational culture & 3.24 & Third \\
\hline Modeling & 3.13 & Forth \\
\hline Employee participation & 3.12 & Fifth \\
\hline Team working & 3.12 & Fifth \\
\hline Senior management commitment & 3.11 & Sixth \\
\hline Knowledge structure & 3.08 & Seventh \\
\hline Staff training & 3.07 & Eighth \\
\hline Performance evaluation & 2.81 & Ninth \\
\hline
\end{tabular}

\section{Discussion and conclusion}

The first hypothesis deals with the organizational culture existence in the implementation of knowledge management in the Bank Hekmat Iranian. Knowledge management is one of the ways to improve the conditions organization for survival. If there were Cultural backgrounds in organizations then this system is run successfully in the organization. The reason for this is that, orientation of Awareness organization is a popular topic and is fully related to human resources and employee's culture in the organization. Therefore, organizations for the successful implementation of a knowledge management system are required to create a culture tailored to the knowledge management system and acting in accordance with the culture.

The findings are consistent with studies following people:

Talebi and Salimi torkamani (2012), Changiz valhamdy (2010), Fatih Mohammadi et.al 2009, monavarian and Tahami (2013), Zand Hessami et.al (2013), Ghasemi and Karimi(2015), Salary et.al (2012), Hossein Abdolmaleki et.al (2013), Vaezi and Moslemi(2010), Hasanzade and Bashiri (2014), Koan(2005), Hong et.al (2005),

These finding are not consistent with studies following people: 
Akhavan et.al (2008), Zeydi and Mirahmadi (2016), Sherma and vikermisange(2002), eskayrem and Amidon(1997), Danport and Prosak(1998), joshi and Aple(2000).

The second hypothesis deals with the Commitment of senior manager's existence in the implementation of knowledge management in the Bank Hekmat Iranian.

The success of any program and planning in the organization is directly dependent on the support and commitment of senior managers.

The findings are consistent with studies following people:

Hadi darmi 2008, akhavan et.al 2008 , talebi and salami torkaman 2012, Changiz valhamdy (2010), monavarian and Tahami (2013), Zand Hessami et.al (2013), Zeydi and mirahmadi (2016), Ghasemi and Karimi(2015), Hasanzade and Bashiri (2014), Hong et.al (2005),

These finding are not consistent with studies following people:

Mohammadi et.al 2009, abtahi and salavati 2006, salary et.al 2012, vaezi and moslemi 2010, Sherma and vikermisange(2002),koan 2005, eskayrem and Amidon(1997), Danport and Prosak(1998), joshi and Aple(2000).

The third hypothesis deals with the Employee participation existence in the implementation of knowledge management in the Bank Hekmat Iranian.

In a creative and knowledge-based organization with a collaborative, is common using the approach of staff and consultation in the framework upgrade systems. This factor also be considered as factors for success in the organization.

By increasing staff awareness about the importance and potential partner's expertise, the staff will increase mutual trust towards each other.

The findings are consistent with studies following people:

Hasanzadeh and bashiri 2014, mohammadi et.al 2009, akhavan et.al 2008, monavarian and tahami 2013, hong et.al 2005.

These finding are not consistent with studies following people:

Abtahi and salavati 2006, hadi darmi 2008, talebi and salimi torkamani 2012, changiz valhamdi 2010.

The forth hypothesis deals with the staff training existence in the implementation of knowledge management in the Bank Hekmat Iranian.

Knowledge and skills are vital for success in job performance. Staff in all units should be trained in the field of focus on generic processes in knowledge management system. Organizing training courses for employees and making them familiar with the concepts of profound knowledge, can guarantee the 
successful implementation of a knowledge management system in the bank Hekmat Iranian. The main prerequisite knowledge management in organization is a continuous education.

The findings are consistent with studies following people:

Hasanzadeh and bashiri 2014, Sherma and vikermisange(2002), mohammadi et.al 2009, koan and vong 2008, hong et.al 2005,

These finding are not consistent with studies following people:

eskayrem and Amidon(1997), Danport and Prosak(1998), joshi and hals aple 2000, abtahi and salavati 2006

hadi darmi 2008, talebi and salimi torkamani 2012, changiz valhamdi 2010

The fifth hypothesis deals with the team working existence in the implementation of knowledge management in the Bank Hekmat Iranian.

Team working proves that the right conditions are created for pluralism in organizational activities. The main elements of problem solving are teams of work. They help the organization to move towards the future. Teamwork is more effective than individual work. For example, in situations that require different skills, teamwork gives better results.

The findings are consistent with studies following people:

Zand hesami et.al2013, hasanzadeh and laya bashiri 2014, akhavan et.al 2008, hong et.al 2005

These finding are not consistent with studies following people:

eskayrem and Amidon(1997), Danport and Prosak(1998), joshi and hals aple 2000, abtahi and salavati 2006,abtahi and salavati 2006 , hadi darami 2008, talebi and salimi torkamani 2012, changiz ,ghamdi 2010.

The sixth hypothesis deals with the empowerment existence in the implementation of knowledge management in the Bank Hekmat Iranian.

Empowering employees are useful to themselves and the organization. They offer the best ideas with a sense of ownership, the excitement and pride in the workplace. They behave responsibly towards their work and their interests are focused on the organization. So that leads to improved process performance and systems.

The findings are consistent with studies following people:

Monavarian and tahami 2013, zand hesami et.al 2013, hasanzadeh and bashiri 2014

The findings are not consistent with studies following people: 
Mohammadi et.al 2009, abtahi and salavati 2006, eskayrem and Amidon(1997), Danport and Prosak(1998), joshi and hals aple 2000.

The seventh hypothesis deals with the Information infrastructure existence in the implementation of knowledge management in the Bank Hekmat Iranian.

Knowledge management is dependent on IT. If this bank wishes to obtain information on the environment and store them for future use in making decisions, this would not be possible or spends a lot of time.

An information system makes it difficult to remove. This system Provides appropriate information to make decision and store this information for the future.

The findings are consistent with studies following people:

Monavarian and tahami 2013, zand hesami et.al 2013,

The findings are not consistent with studies following people:

Mohammadi et.al 2009, abtahi and salavati 2006, salary et.al 2012, vaezi and moslemi 2010, eskayrem and Amidon(1997), Danport and Prosak(1998), joshi and hals aple 2000.

The eight hypothesis deals with the performance evaluation existence in the implementation of knowledge management in the Bank Hekmat Iranian.

Staff performance evaluation system is a tool of the authorities. These tools can be used to achieve organizational goals. According to the organization's success depends on its compatibility with the environment, successful performance evaluation system would be flexible and change according to organizational changes.

The findings are consistent with studies following people:

Zand hesami et.al2013, zeydi and mir ahmadi 2016, hasanzadeh and bashiry 2014, koan and vang 2005 ,

The findings are not consistent with studies following people:

eskayrem and Amidon(1997), Danport and Prosak(1998), joshi and hals aple 2000, zeydi and mir ahmadi 2016

The ninth hypothesis deals with the modeling existence in the implementation of knowledge management in the Bank Hekmat Iranian.

Modeling or patterning is the process of finding and implementing best practice the typical definition for this term is "Search for the best industry practice that leads to exceptional performance through the implementation of" 
One of the points in this area, quick access to the best solution.

The findings are consistent with studies following people:

Changiz valhamdi 2010, zand hesami et.al 2013, zeydi and mirahmadi 2016, hasan zadeh and bashiri 2014,

The findings are not consistent with studies following people:

eskayrem and Amidon(1997), Danport and Prosak(1998), joshi and hals aple 2000

The tenth hypothesis deals with the knowledge structure in the implementation of knowledge management in the Bank Hekmat Iranian.

Formal knowledge is presented in the form of reports, agendas, programs and regulations Informal knowledge is presented in the form of knowledge-based systems, issue-based information systems, analysis meetings and official letters. Knowledge Extract from data and structured data sources. Structured data sources include: databases, knowledge bases, data warehouses and data markets and commercial centers.

Knowledge leads to creating value for organizations using impact on products, processes and human resources.

Knowledge management, information, data and intellectual property becomes the enduring and lasting value and knowledge-based organizations leads to scientific enhancement of generation and research level to improve the quality and quantity of products.

The findings are consistent with studies following people:

Abtahi and salavati 2006, hong et.al 2005

The findings are not consistent with studies following people:

Mohammadi et.al 2009, salari te.al 2012, vaezi and moslemi 2010, Sherma and vikermisange(2002),koan 2005, eskayrem and Amidon(1997), Danport and Prosak(1998), joshi and hals aple 2000

\section{Comments on results}

According to the test result, the first hypothesis refers to this fact that the bank Hekmat Iranian has provided free discussion and exchange of ideas about the objectives, strategies and policies needed Therefore, the cooperation and support of all sectors and units there in the event of changes. Teamwork and knowledge sharing and trust among employees is approved by the bank.

According to the test result on the second hypothesis, it is necessary that senior managers identify clearly their intentions with the implementation of a knowledge management system. 
Provide guidance to employees, to support knowledge management project and relevant policies senior managers should be more efforts in this regard.

According to the third hypothesis test result, it is necessary to encourage the active participation of staff in decision making and planning, Staff involved in assessing the knowledge management system, all employees are required to participate in the knowledge environment. Also, create conditions where all employees feel their responsibility to participate in this.

According to the fourth hypothesis test result, the need to provide bank procedures, equipment and training facilities for the purpose of knowledge management. Create a school environment in the bank, Encourage employees to participate in training courses within and outside the organization, Education experts have a professional educator, specialized units held for the implementation of knowledge management in the bank.

According to the fifth hypothesis test result encouraged the formation of work teams, will be linked to the knowledge and experience of teamwork with each other. This is the assessment of coordination, cooperation and team performance in the implementation of knowledge management.

According to the sixth hypothesis test result, empowerment is done in order to empower employees to improve organizational commitment.

According to a seventh hypothesis testing, information infrastructure creates friendly methods for users of the system, these banks, have developed a knowledge management system information technology infrastructure. Also, these capabilities have been used to implement a knowledge management system.

According to the eighth hypothesis test result, meaning that performance measurement is essential in the bank there is a serious need to improve the effectiveness of performance evaluation Also, it should be considered in evaluating the performance of individuals and groups impartiality, be considered real rewards for improved performance.

According to the ninth hypothesis test result, it is necessary to provide guidelines for the use of efficient patterns. Staff are encouraged to emulate the best practices in other banks. The Bank is also establishing a stable pattern for systems of staffing, budgeting, etc.

According to test tenth hypothesis, this need that the bank be created a structure based on knowledge exchange with members of the Bank as well as suppliers. Create a body of knowledge for knowledge sharing with customers, It also created a body of knowledge based on the abilities and capabilities of individuals.

The following are suggested for future research:

1. Given the importance of knowledge management, it is recommended to evaluate other infrastructural factors that could affect components of knowledge management as well as the impact on banking services 
2. It is recommended that Hong model compare with other models such as Wang and Espinvall

3. It is suggested that this study be used in other public and private banks

\section{References}

[1] Akhavan,Peyman, Zahedi, mohammad reza, najmi, ali(2012)" The key success factors of knowledge management in the automotive industry supply chain in Iran" Future management, S.10, No 26

[2] Abtahi,Hossein,salavati,Adel(1922) “ Knowledge management in organization” Tehran: Peyvan No publishing, First Edition

[3] Fatih Mohammadi,Asghar(2008). Graduate thesis," Identify key factors in the success of a knowledge management system in colleges, higher education institutions management in Tehran" Higher Institute of Education and Research Management

[4] Darmi, Hooman(2008), Graduate Thesis, " Factors Affecting on success of a knowledge management system in projective organizations" faculty of management, University of tehran

[5] Talebi Kambiz, Soleymani Azar, Mehdi (2012) "Prioritize the most important factors in the success of knowledge management systems in small and medium firms" Journal s of economics and New business, No.14, Fall 2009, Page 12.

[6] Abdolmaleki Hossein, Sadat mirzazadeh, Zahra Sadat, Alidost farokhi, Ebrahim (2015), "Review and prioritize the factors affecting the establishment of a knowledge management system on the Youth and Sports Ministry" no.4, Winter 31, Pages 95.

[7] Salary, Nasibeh, Por serajian, Daryosh, Saleh oliya, mohammad, Shokohy, Shahram (2012), "Determine and prioritize the factors affecting the success of knowledge in science and technology parks", Journal of parks and incubators, S.7 , No.27

[8] Valmohamadi, changiz (2010) "Identifying and prioritizing key factors in the successful implementation of knowledge management systems in small and medium businesses " journal of management, No 16, years 6, Pages 99 